\title{
Developing Professional Foreign Language Skills through Webinars as Online Tool
}

\author{
Svetlana Fetisova $^{1^{*}}$, Elizaveta Podkamennaya ${ }^{2}$, and Ksenia Nevolina $^{3}$ \\ ${ }^{1}$ Institute of Linguistics and Intercultural communication, National Research Technical University, Irkutsk, Russia \\ ${ }^{2}$ Faculty of Service and Advertising, Irkutsk State University, Irkutsk, Russia \\ ${ }^{3}$ Faculty of Management, Logistics and Customs Affairs, Irkutsk State Railway Engineering University, Irkutsk, Russia
}

\begin{abstract}
This work is devoted to the technology of teaching students to organize and conduct webinars as contributing to their motivation and improving their performance when developing professional foreign language skills. Utilizing webinars encompasses both turning the focus from the teacher-centered approach toward learner-centered one and studying outside the classroom effectively. The research presented was carried out at two universities in Irkutsk, Russia: Irkutsk State Linguistic University (2014-2015) and Irkutsk State University (2017). 45 students of the Universities with the major "Advertising and Public Relations" were the participants of the learning experiment. The sign test, Mann-Whitney-Wilcoxon U-test, were employed to confirm the results of the testing.
\end{abstract}

\section{Introduction}

Nowadays, the processes of globalization and IT penetration in all spheres of life provide new technologies and opportunities, as well as generate challenges and new demands. In terms of higher education, the new requirements call for updating professional training of specialists in the context of innovative learning environment resources and breakthrough methods and techniques. Unlike the traditional instructive way of learning where the teacher is a key person (teacher-centered method), the approach encourages interest in the profession; promotes the efficient acquisition of training material; forms patterns of conduct; provides high motivation, strength, knowledge, team spirit and freedom of expression; and most importantly, contributes to the complex competences of future specialists. Hence, teachercentered teaching methods have been rendered obsolete.

Group discussion, individual presentation, assignment, seminars, workshops, role play and case study are various common interactive methods used in classroom teaching. Whereas in a distance learning process, the teacher stays in one location and provides notes and instructions and students learn lessons by staying, another convenient location as required. That is what meets the requirements of the main strategy of modern education - the focus on the student's independent activity, the organization of self-learning environments and experimental and practical training, where students have a choice of activity and can use initiatives as well as flexible training programs where students can work in a comfortable rhythm. "Internet generation" students like to interact in a collaborative environment, which facilitates the understanding and learning as it involves students' more active and creative approach to tasks.

With the application of distance learning technologies, there appear such interactive teaching forms as online conferences, collaborative work on the class project, public presentation of the project and discussions in the online mode, behavioural modelling, peer feedback, etc. Many interactive technologies including web based or internet based learning and teaching are the main feature of the learner centered teaching.

The need to utilize interactive forms of learning is becoming more urgent concerning studying foreign languages at nonlinguistic universities. The fact is determined by the traditional methods not being able to solve the problem of raising interest to learn languages and removing difficulties that emerge when studying a minor curriculum subject. Webinars - seminars conducted in the online mode - are among the interactive learning forms mentioned above, as they help generate positive motivation and the technology intensive multimedia factor.

The article is aimed at exploring the theory and practical aspects of the problem of interactive learning taken as a whole and webinars prepared and hosted by students as one of the interactive forms to learn foreign languages.

\section{Literature review}

There have recently been a number of publications devoted to interactive learning. The forms and the content of interactive learning are described in research

\footnotetext{
* Corresponding author: s fetisova@mail.ru
} 
by M. Malik [1], Karen V. Pincus [2], Elsayed Y. Elsayed [3], B. Hemmings [4], F. Bengstsson [5], P. Schmidt [6], etc.

The researchers agree that the modern system of education puts the focus on learners' interests, communication, as well as social oriented aspects of learning, and these requirements can be satisfied through utilizing interactive techniques. So, D.V Dobrinina considers that the priorities and ways to contribute to raising students' interest in the subject, making no gap between the studies and practical aspects of everyday life, and teaching to acquire social skills [7]. The researchers note that interactive methods are able to solve a wide variety of problems concerning teaching foreign languages. They are as follows: it allows the students to immerse into the authentic environment; to develop creative skills as well as self-guided skills; to communicate with peers and teachers; to make free of numerous sources of information and variants of language as well as various learning content. It gives the opportunity to communicate with the wider world; it creates new conditions for self-learning and individual learning path; it delivers the learner-centred approach; it allows teachers to plan and organize training courses in consort with students as well as it allows students to have an influence on the choice of learning content. It eliminates restrictions particular to traditional teaching methods as it expands the boundaries by studying outside the classroom.

Webinars appear to be one of the most effective forms of interactive learning in higher education level institutions. A webinar (abbreviation from «web-based seminar») represents an online event (a seminar, conference, lecture, training course, video presentation, etc.) that is organized by means of web-technology in the online mode. A webinar is a tool to achieve various purposes. Broadly speaking, webinar is used to achieve the following goals: for pedagogic influence; to organize distance learning; as a means of holding different events; as a means of getting education. Taking a narrow view, a webinar also can be used for teaching languages. One cannot pass over the fact that nowadays webinars are mostly considered to be a vehicle to transfer knowledge from teachers to students.

A webinar is a comparatively new but trending tool to organize learning process in the online mode due to such features as accessibility (geographical, disciplinerelated, or quantity-related); an individual approach, the possibility of individual learning path as well as its economic efficiency.

Therefore, the relevance of the problem of employing interactive learning in general and a high demand for webinars as one of its innovative forms to teach foreign languages in particular is obvious. As a whole, the analysis of all the research undertaken recently reveals that the problem of organizing webinars within the foreign language lessons in nonlinguistic universities is immature. Just a few researches have been devoted to the experience of conducting webinars at English lessons. Moreover, no research to describe students' experience to hold webinars has been found.

\section{Materials and methods}

The materials and methods used are determined by the purpose of the research. Following on from the purpose of the research, a wide range of theoretical sources devoted to webinars as an effective form of interactive learning were analyzed and summarized. The authors of the article facilitated some webinars and the research put the focus on their results as well as other interactive projects aimed at learning foreign languages in nonlinguistic universities. The research was based at Irkutsk Universities: Irkutsk State Linguistic University (2014-2015) and Irkutsk State University (2017). 45 students of the Universities with the major "Advertising and Public Relations" were the participants of the learning experiment.

The research is targeted at developing technology to teach students to conduct webinars. The key principles of the research are profiling and interdisciplinarity implemented by information receptive and problembased learning methods. Technology is understood as "a set of the most advantageous ways of work management to achieve a desired learning goal in minimum time with the least trouble while being cost-effective" [8].

The 'organize-and-conduct-webinars' technology developed by the authors includes a sequence of exercises that are subdivided into receptive reproductive, reproductive, productive stages.

The process starts with the preliminary stage to develop a theoretical foundation and positive attitude to the activity. This stage is responsible for learners to recognize terms and understand characteristic aspects of organizing and conducting webinars. Besides, the rules of English and Russian speaking etiquette in the professional sphere are introduced in the preliminary stage.

In the initial stage, the foundation for the interactive discussion is a selected text in the foreign language. It gives insight into the ways how to utilize webinars and highlights the significance of webinars as a means of professional communication. Students share their experience of having participated in webinars and answer the question why companies set up such events.

Then students are offered to watch a free access webinar in English (e.g. on YouTube) on a relevant topic in order to discuss them afterwards. The outline of the discussion is reflected in the questions: what are the sections of the webinar; what are the host's behavioral peculiarities; what interactive methods of building good rapport with the audience are employed; what secrets of using the chat and making a presentation are there; what is the way to ask and answer questions; what other webinar instruments are there? Moreover, after the viewing, students have to choose and analyze some other webinars on their own.

In the view of this, receptive exercises are the leading activity in the preliminary stage. But that does not exclude creativity as students' choosing webinars suitable to the task, their analysis and mapping out their structure activate learners' intellectual processes while demanding a creative approach. 
Let us introduce an example of the preliminary stage exercises:

Task 1: Do a one-page analysis, "filling in the blanks" for the following questions:

1. The topic of the webinar, the source and the date

2. Introduction phrases

3. Number of slides per minute

4. Interaction tools used by the presenter:

a. Chat

b. Raising hands

c. Questionnaires

d. Other

5. Concluding phrases

Task 2: Present the results of your analysis to the group.

The basic learning stage - acquiring and consolidating skills and abilities - is geared with receptive, receptive reproductive, and productive exercises.

The receptive exercises are aimed at guiding the ability to analyze the compositional structure of a webinar, its parts as well as a means of verbal influence. Receptive exercises allow students to deepen knowledge gained in the preliminary stage. Students continue learning grammar and stylistic rules necessary for different parts of webinars; mastering how to build headings and texts in slides; getting knowledge of speech fundamentals, types of speech and speaking etiquette. They have to know means and methods of linguistic manipulation; various strategies of grasping the target audience's attention; general and specific aspects of professional communication both in English and Russian. In the basic stage, productive, problem-related and discovery learning methods are used.

The exercises of receptive reproductive type navigate the ability to reproduce compositional parts of webinars. This stage also allows students to improve their skills and develop their abilities to use certain language aspects in a corresponding style; design the idea verbally; use necessary strategies to build statements; anticipate the result and pursue the policy they need.

The key methods of reproductive exercises are problem-related, discovery learning and reproductive. Students are to define aims and conditions of linguistic manipulation; spot the target audience and outline the content of their webinar (its parts).

This stage is responsible for learning how to conduct webinars is intended to use the acquired knowledge and formed skills in the process of preparing individually and conducting a webinar. They are reproductive, problemrelated and discovery learning methods that make it possible to achieve the aim.

Developing the appropriate attitude to the activity starts in the preliminary stage and goes through all the learning process. In the process after collecting information; reading texts on rules to organize and conduct webinars as well as on technical features of the chosen platform and watching videos students are to arrange a step-by-step instruction "How to hold a webinar" outlined in three stages. In other words, students map out a route of sequential actions to realize the performance targets:
Part 1. Preliminary stage

a. Advertise your webinar by creating an announcement page with a short description of the event;

b. Send out invitations 1 week before the beginning and a reminder 1 day and 1 hour before the webinar;

c. Make a presentation and prepare your speech:

- Don't use small font size;

- Create one slide for 2-3 minutes of your speech;

- It's acceptable to use more text than usual;

- Visualize and animate your presentation;

- Make your speech dynamic and clear;

- Avoid slang and jargon;

- Rehearse, rehearse, rehearse!

Part 2. Webinar on air

a. Greet the audience and check their presence;

b. Ask them to turn off their microphones and cameras;

c. Look straight into the camera;

d. Don't make long pauses;

e. Interact with your audience during the whole webinar by asking them questions they should answer in chat;

f. After the presentation, invite questions via either chat or microphones. Answer the questions orally.

Part 3. Summing up

a. Edit the video record;

b. Send out certificates and the link to the video record.

The plan (route) mentioned above is used in the final stage, that is a stage of quality control and implementation. Students (in large or small teams) choose a relevant professionally oriented topic for their webinar. For instance, within our research, students were preparing the following web-events: Trends in Graphic Design of Creating a Printable Ad; Psychology of Color in Marketing and Branding; How to Promote Internet Service; How to Become a Copywriter and Earn Money with no Experience; SMM in VK - Basic Tips Based on Real Experience.

To participate in a webinar, one has to be equipped with the following: a device with web browser (a net access computer, tablet, laptop or smartphone), computer headset with microphone, web camera. Participants connect to the virtual room at a pre-arranged time by means of conventional software to appear in the virtual "audience" with all the attendees. One can connect to the webinar any time it is on air.

There is a wide range of technical service platforms to hold a webinar (MicrosoftOfficeLiveMeeting, AdobeAcrobatConnect, BeamYorScreen, Quatla, Webinar.ru, MirapolisVirtualRoom, BigBlueButton, eTutorium,IPTV, DreamStudy, VirtualAcademia, etc. From a practical perspective, the procedure of choosing a proper platform is based on three priority criteria: the objective, cost and functions. Various platforms, both locally produced and foreign ones, offer certain options: a set price policy (from high to no-cost tariffs); a set 
number of participants (from 4-5 to 1000 and even more); different sets of available instruments, etc.

When carrying out our project, we build on, first of all, the criterion "the objective" - to utilize the webinar where the student is a key figure, a moderator of the online broadcasting. So, we go by the overall simplicity of customization and functions. The criterion of no small importance for the learning process is "cost" when the event has to be economical and cost effective. Hence, following the three criteria (the objective / functions / cost), we choose the platform Google Hangouts that meets the requirements and has easy enough settings, however, it is well-equipped to hold a webinar of high quality (video / presentation / chart / animation services). Moreover, it does not have the requirement to install special software in the computer. So, it is accessible to the public and is one of the most popular no-cost platforms.

While preparing for the webinar, students are to declare chosen topics in the forum in the educational portal of the university and confirm the time of the webinar on air. Then they work out an announcement of the event and send out invitations to their group mates and other alleged participants through social networks, email or the educational portal. As experience has proven, social networks hold the top spot in the list of communication methods among the youth audience. All the invitations are delivered a week before the webinar. They are repeated a day and an hour before the event starts.

It is necessary to test the functions of the platform beforehand for the webinar to be successful. Without doing so, there is a major risk to have technical problems, the so called 'cannots': you cannot download or page through the presentation; the moderator cannot see the chat; the audience cannot hear the moderator; the moderator or participants cannot connect to the webinar on time. Participants are recommended to switch off microphones and cameras to improve the quality of the communication.

A presentation, chat-based communication, as well as answering questions at the end are requirements when holding a webinar. It is necessary to focus students' attention on the fact that the chat should be used throughout the webinar and on the following chat techniques:

- Put a "+" if you agree with the statement....;

- Grade the importance of the presented information from 1 to 10 ;

- Put a "+" if you have ever experienced ......;

- Choose the correct answer and put its number in the chat.

The techniques contribute to grasping the audience's attention and have a close contact with the moderator.

After the webinar, students are to send out participation certificates. Google Hangouts gives the opportunity to save and edit the event video recordings. The student moderator can share a link with the participants as is done by experienced webinar professionals.
The grading system for webinars is based on the four-point marking scale with the criteria: the foreignlanguage-for-specific-purposes skill level, webinar compliance, interactive flow of communication, the skill to deal both with make-ready and spontaneous questions.

\section{Results}

The technology of teaching to organize and conduct webinars described in the research was tested during the experimental learning, which was conducted among the sophomores of the Faculty of Social Sciences of Irkutsk State Linguistic University in the second semester of 2014-2015 academic year and sophomores of the Faculty of Service and Advertising of Irkutsk State University in the second semester of 2016-2017 academic year.

The theoretical basis of the experimental training comprises theoretical works of S.F. Shatilov [9], M.V. Lyakhovitsky [10], E.A. Shtulman [11], V.I. Zagvyazinsky [12] and has been carried out in accordance with the requirements for this type of scientific and methodological research.

It was a natural experiment and was held within the framework of the ESP course during four weeks. The experiment involved 25 students of Irkutsk State Linguistic University and 20 students of Irkutsk State University, a total of 4 groups. One of the groups in each University was experimental, and the other a control one.

The experiment consisted of three stages: the preparatory stage, the experiment itself, and the postexperimental stage.

The following activities were carried out during the preparatory phase of the experimental learning:

1. Monitoring of the educational process in two parallel academic groups in order to identify the level of students' knowledge of English to determine experimental and control groups.

2. Interviewing students to identify their knowledge about webinars, practical experience of participation and motivation to master the skills of their organization and conduct.

3. Pre-experimental test to determine the initial level of foreign language professional communicative competence and skills of organizing webinars in experimental and control groups.

Monitoring showed that students in both groups had approximately the same level of English, which met the requirements for the selection of experimental (EG) and control groups (KG). To determine the statistical indistinguishability of students of EG and CG, we used Mann-Whitney U-test. This test is intended to assess the differences between two small samples [13].

The results of interviewing the students showed that $90 \%$ of them have a general idea of what a webinar is; while only $10 \%$ of respondents were able to explain the importance of webinars for their professional activities, $70 \%$ limited to describing the webinar as a type of online learning, $10 \%$ believed that webinars are a marketing method of making money, $10 \%$ of respondents found it difficult to answer. 
Regarding practical experience of participating in webinars, $45.5 \%$ of students at least once took part as a listener, $54.5 \%$ of them needed it as a part of some training. $100 \%$ of respondents expressed their desire to learn how to conduct webinars in English.

For preexperimental test, the students were offered a set of questions and tasks, as the results of which the first group was chosen to be the experimental group (EG), and the second - to be the control one (CG).

To test the effectiveness of the technology developed by us, the following criteria were selected: the level of proficiency in ESP, compliance with the rules of organising webinars, interaction with listeners, the ability to answer questions of a prepared and spontaneous nature, the design of the post-event stage.

On the basis of these criteria, three levels of development of the skills of organizing and conducting webinars in English were identified. A table of indicators for each criterion was compiled to determine the level.

Each of the criteria was evaluated on a scale from 0 to 20 points during three monitoring tests. The distribution of the scores for the levels is presented in the table (Table 1):

Table 1. Criteria of development of the skills of organizing and conducting webinars.

\begin{tabular}{|c|c|c|c|c|c|}
\hline \multirow[b]{2}{*}{$\frac{n}{d 0}$} & \multicolumn{5}{|c|}{$\begin{array}{c}\text { Criteria of development of the skills of organizing } \\
\text { and conducting webinars }\end{array}$} \\
\hline & 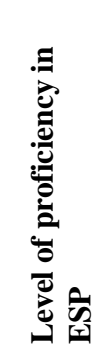 & 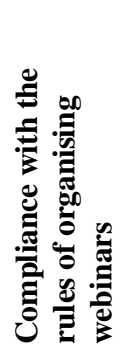 & 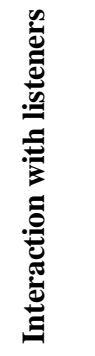 & 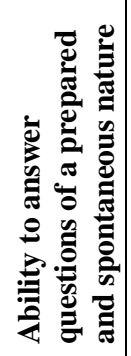 & 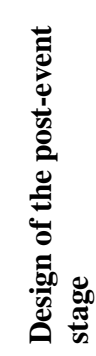 \\
\hline $\begin{array}{l}\text { Low } \\
0-69 \\
\text { scores }\end{array}$ & $\begin{array}{c}0-14 \\
\text { points }\end{array}$ & $\begin{array}{c}0-14 \\
\text { points }\end{array}$ & $\begin{array}{c}0-14 \\
\text { points }\end{array}$ & $\begin{array}{c}0-14 \\
\text { points }\end{array}$ & $\begin{array}{c}0-13 \\
\text { points }\end{array}$ \\
\hline $\begin{array}{l}\text { Mediu } \\
\text { m 70- } \\
84 \\
\text { scores }\end{array}$ & $\begin{array}{l}14-17 \\
\text { points }\end{array}$ & $\begin{array}{l}14-17 \\
\text { points }\end{array}$ & $\begin{array}{l}14-16 \\
\text { points }\end{array}$ & $\begin{array}{l}14-17 \\
\text { points }\end{array}$ & $\begin{array}{l}14-17 \\
\text { points }\end{array}$ \\
\hline $\begin{array}{l}\text { High } \\
85-100 \\
\text { scores } \\
\end{array}$ & $\begin{array}{l}17-20 \\
\text { points }\end{array}$ & $\begin{array}{l}17-20 \\
\text { points }\end{array}$ & $\begin{array}{l}17-20 \\
\text { points }\end{array}$ & $\begin{array}{l}17-20 \\
\text { points }\end{array}$ & $\begin{array}{l}17-20 \\
\text { points }\end{array}$ \\
\hline
\end{tabular}

The table reflects the level of development of each skill in accordance with the selected criteria.

To track the dynamics, two control tests were used: intermediate and final. As a result of the intermediate test, the EG showed significant progress compared to the pre-experimental test; $20 \%$ of students demonstrated a high level of webinar organising skills development, $60 \%$ - medium, $20 \%$ - low. The results of the test in CG showed that students had a vague idea of the webinar format and were hardly able to speak about the structure of webinars. It is obvious that the idea of how to organize webinars for students of this group has not changed in the learning process. $10 \%$ of students demonstrated a high level of formation of these skills, $40 \%$ - average, $50 \%$ - low.

The results of the final test in the EG showed a higher level of webinar organising skills development. The students of CG also improved their results, but not considerably (Fig.1).

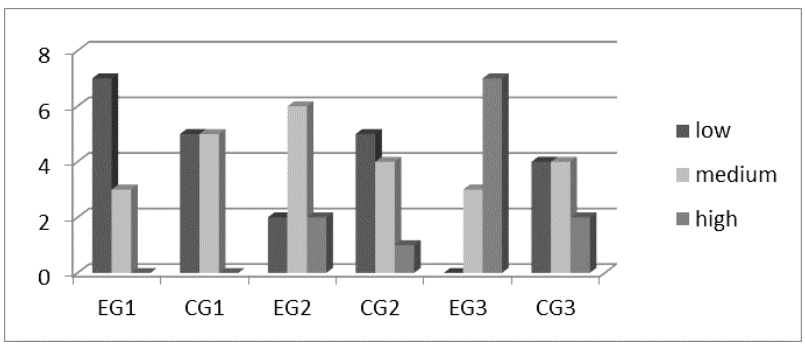

Fig. 1. Dynamics of the levels of webinar organising skills development according to results of the three tests (the experimental data of the 2016-2017 academic year).

In order to prove the effectiveness of the experimental learning, we had to identify a statistically significant tendency in the displacement of the values of each indicator. To do this, G-signs criterion was used [13], which gives the opportunity to determine how similarly the characteristic values in repeated measurement of the associated homogeneous sample change. Processing of data on this criterion showed statistically significant changes in the EG in all parameters both at the stage of intermediate test and by the end of training. In the CG, no changes were revealed.

In order to determine the dynamics of the development of the criteria in the CG, a more powerful tWilcoxon criterion was applied, which allowed establishing not only the direction of the changes, but also their degree. The results of calculations showed that in the CG there were statistically significant changes only on the second criterion, and in the EG on all criteria.

Table 2. Indicators of Mann-Whitney criterion calculations.

\begin{tabular}{|l|l|c|c|c|}
\hline & $\mathbf{U}$ & $\mathbf{p} \leq \mathbf{0 . 0 1}$ & $\mathbf{p} \leq \mathbf{0 . 0 5}$ & $\begin{array}{l}\text { Significance } \\
\text { insignificance }\end{array}$ \\
\hline Criterion 1 & 25 & 19 & 27 & ? (ambiguity) \\
\hline Criterion 2 & 12 & 19 & 27 & 1 (Significance) \\
\hline Criterion 3 & 16 & 19 & 27 & 1(Significance) \\
\hline Criterion 4 & 15 & 19 & 27 & 1 (Significance) \\
\hline Criterion 5 & 13 & 19 & 27 & 1 (Significance) \\
\hline
\end{tabular}

The Mann-Whitney criterion was again applied to confirm the results, revealing the differences between the EG and the $C G$ after the experiment (Table 2).

\section{Conclusion}

Studies of theoretical and practical material on the problem of organizing and holding such interactive forms of training as a webinar allows us to conclude the following. Ongoing reforms of higher education and the requirements of information and communication technologies contribute to the development and implementation of new effective methods and forms of 
interaction in education, making qualitative changes in the teacher-student relationship, in which student is given an active role of the subject, seeking permanent self-development. Such changes are possible mainly due to the interactive means of learning with the use of distance learning technologies. One of the most effective and relevant forms of modern interactive teaching a foreign language (English) in non-linguistic universities implementing a competence approach is a webinar, organized by students.

This innovative form of education has many advantages over traditional forms, as it is aimed at productive study of a foreign language, excludes mechanical transfer of knowledge and involves all participants of the educational process, contributing to the improvement of both general and professional competencies. It should be noted that the leading role of students in webinar develops the ability to take the initiative, be responsible for their own decisions, generate new ideas, gain new experience, analyze their capabilities, contributes to the accumulation and transmission of knowledge and experience of students. Preliminary work allows students to get a broad understanding of the topic of their interest, independently acquire and use in practice new knowledge and skills, as well as improve the competences necessary for their professional activities: teamwork, the ability to present the results of intellectual activity, marketing skills (business promotion, image events, expert opinion), etc.

From the point of view of the practical implementation of the results of the study, the plan of organising webinars developed by the authors can be adopted by both teachers and students of the field of Advertising and PR. In addition, they can be useful for other specialists in the field of higher education, general public, and can serve as a material for further improvement of innovative forms of interactive learning, organized and implemented by students.

We would like to thank Claudia Lahr, Fulbright English Teaching Assistant at Irkutsk State University for her support, writing assistance, language editing, and proofreading.

\section{References}

1. M. Malik, Irfan. N. Umar, Ahmad M. Salbani, W. Ahmad J. Wan Yahaya, Procedia - Social and Behavioral Sciences 197, (2015)

2. K.V. Pincus, D.E. Stout, J.E. Sorensen, K.D. Stocks, R. A. Lawson, Journal of Accounting Education, 40, 1-18 (2017)

3. E.Y. Essayed, La Lopa, Peer Reviewed Paper Proposal, (2016)

4. B. Hemmings, R. Kay, B. Murphy, S. Elliott, Journal of Further and Higher Education 41, 5 (2017).

5. F. Bengtsson, M. Granmo, The FASEB Journal (2017)

6. P. Schmidt, J. Pittner, Otkrytoe obrazovanie 5, (2013)
7. D.V. Dobrynina, Vestnik Buryatskogo gosudarstvennogo universiteta 5, (2010)

8. E.G. Azimov, Thesaurus of methodological terms (theory and practice of teaching languages), (Zlatoust Publ., St. Petersbourg, 1999)

9. S.F. Shatilov, Methodology of teaching German in secondary school (Prosveshhenie Publ., Moscow, 1986)

10. M.V. Lyakhovitsky, Methods of teaching languages (Vyssh. shk. Publ., Moscow, 1981)

11. E.A. Shulman, Methodological experiment in the system of research methods (VGU Publ., Voronezh, 1999)

12. V.I. Zagvyazinskij, Learning theory: modern approach (Akademiya Publ., Moscow, 2001)

13. D.A. Novikov, Statistical methods in pedagogic research (benchmark case) (MZ-Press Publ., Moscow, 2004) 